Günter Kahlert

Steuerliche Aspekte der GmbH-Sanierung

Steuerfolgen von Sanierungsmaßnahmen vor und nach Insolvenzeröffnung 


\section{RWS-Skript 384}




\section{Steuerliche Aspekte der GmbH- Sanierung}

Steuerfolgen von Sanierungsmaßnahmen vor und nach Insolvenzeröffnung

2015

von

Dr. Günter Kahlert, Rechtsanwalt Steuerberater, Hamburg

\section{RWI}

RWS Verlag Kommunikationsforum GmbH · Köln 
Die Deutsche Nationalbibliothek verzeichnet diese Publikation in der Deutschen Nationalbibliografie; detaillierte bibliografische Daten sind im Internet über http://dnb.d-nb.de abrufbar.

\section{(C) 2015 RWS Verlag Kommunikationsforum GmbH}

Postfach 2701 25, 50508 Köln

E-Mail: info@rws-verlag.de, Internet: http://www.rws-verlag.de

Alle Rechte vorbehalten. Ohne ausdrückliche Genehmigung des Verlages ist es auch nicht gestattet, das Werk oder Teile daraus in irgendeiner Form (durch Fotokopie, Mikrofilm oder ein anderes Verfahren) zu vervielfältigen.

Satz und Datenverarbeitung: SEUME Publishing Services GmbH, Erfurt Druck und Verarbeitung: Hundt Druck GmbH, Köln 